\title{
PSICOMOTRICIDADE FUNCIONAL E A EDUCAÇÃO MUSICAL: UMA PROPOSTA “PERCUSSIVAMENTE” CORRETA
}

\author{
Augusto Paulucci Ribeiro, Janaína Pereira Duarte Bezerra \\ Universidade do Oeste Paulista - UNOESTE, Presidente Prudente, SP. E-mail: janainapereira@unoeste.br, \\ augustopr@hotmail.com.
}

\section{RESUMO}

O presente artigo tem como objetivo refletir, através de um estudo bibliográfico, e de situações vivenciadas corriqueiramente, como a psicomotricidade bem desenvolvida na criança pode beneficiá-la na prática de instrumentos de percussão e bateria. Aproximando a psicomotricidade funcional da prática percussiva, veremos como a psicomotricidade está presente no mundo da percussão, e apresentaremos como é possível desenvolver um trabalho que irá contribuir com uma melhora no quadro psicomotor da criança.

Palavras-chave: Educação musical. Psicomotricidade funcional. Estudante de percussão.

\section{FUNCTIONAL PSYCHOMOTOR AND MUSIC EDUCATION: A PROPOSAL "PERCUSSIONLY" CORRECT}

\section{ABSTRACT}

The present article aims to reflect, through a bibliographical study, and commonly experienced situations, how the well developed psychomotricity in the child can benefit it in the practice of percussion instruments and drums. Approaching the functional psychomotricity of the percussive practice, we will see how the psychomotricity is present in the world of the percussion, and we will present how it is possible to develop a work that will contribute with an improvement in the psychomotor picture of the child.

KEYWORDS: Music education. Functional psychomotricity. Student of percussion.

\section{INTRODUÇÃO}

Refletindo acerca das diferentes áreas da ciência que revelam pontos em comum quanto à algumas características, destacamos a psicomotricidade que, assume -se como uma ciência capaz de revelar a condição do indivíduo a partir das distintas características dos aspectos motor, afetivo, cognitivo, emocional e social que o compõe.

A psicomotricidade nos mostra que o homem é o seu corpo, que existe a real possibilidade do homem dominar, controlar e educar o seu corpo. Não consideramos o dualismo cartesiano, por entendermos que 0 problema maior não está na existência ou não do dualismo e sim na dificuldade psicomotora do indivíduo.

Nessa direção temos,

Não se trata de justapor a alma e o corpo, nem mesmo de sutelizas semânticas ("psicossomática",

"complexo corpopsiquismo"), mas de deslocar a problemática cartesiana e reformulas as relações entre a alma e o corpo, que toda a filosofia clássica coloca em mútua oposição, mesmo quando afirma, por vezes, sua unidade. Ora, é com as palavras dessa filosofia (nossa cultura ocidental) que continuamos a refletir sobre essa problemática (COSTE, 1978, p.09)

Por não ser uma área tão conhecida entre os profissionais da educação, de modo geral, algumas pessoas ficam presas a um conceito equivocado do termo, criado a partir de sua fragmentação, e o compreendendo como a ciência que relaciona corpo e mente, já que 
"psico" se volta à compreensão de mente e "motricidade" à compreensão de corpo.

Essa condição de compreensão, não é suficiente para conceber a psicomotricidade em sua totalidade pois "se o essencial fosse a definição, deveria bastar dizer o que é a psicomotricidade para captar-lhe a essência e, com ela, a extensão e a compreensão" (CHAZAUD,1976, p. 11).

Fica claro que o importante não está apenas em saber qual o conceito de psicomotricidade, mas o essencial conseguir compreendê-la.

Acreditamos que muitos trabalhos voltados à psicomotricidade não se efetivam de forma satisfatória, pois segundo TAVARES (2007, p. 3)

os profissionais da área
educacional demonstram
um certo despreparo para
trabalhar com o
desenvolvimento
psicomotor da criança,
principalmente quando
esta inicia sua vida escolar
e também no decorrer da
mesma.

$\mathrm{Na}$ maioria das vezes, é comum encontrarmos educadores afirmando que uma criança é "estabanada" ou "desastrada" e por isso deve ser encaminhada ao professor de educação física, pois o seu problema é físico ou corporal; e quando uma criança apresenta distúrbios em seu comportamento ou dificuldade de aprendizagem costuma-se dizer que o seu problema é emocional, encaminhando-a ao psicólogo da escola, ou a outros profissionais que atuam além dos muros da instituição.

Outro elemento que a nosso ver implica no trabalho efetivo da psicomotricidade é a compreensão acerca das perspectivas de psicomotricidade que são a terapia psicomotora, a reeducação psicomotora, a psicomotricidade funcional e a psicomotricidade relacional.

Cada perspectiva citada tem características específicas, o que determina formas diferenciadas de realização prática do trabalho. Dentre elas, abordaremos a psicomotricidade funcional que segundo TAVARES (2007) sustenta-se em diagnósticos do perfil psicomotriz e na prescrição de exercícios para sanar possíveis descompassos do desenvolvimento motor. A estratégia pedagógica baseia-se na repetição de exercícios funcionais, que são estereótipos criados e classificados constituindo as famílias de exercícios. O psicomotricista comanda, não interage, é o modelo da criança.

Desta forma, a construção deste artigo parte da minha experiência enquanto professor de instrumentos de percussão que me proporcionou condições de detectar dificuldades psicomotoras em alguns alunos no momento de aprendizagem dos referidos instrumentos.

Partindo dessa situação, buscamos explicar o motivo pelo qual é possível a ocorrência de tais dificuldades, com o intuito de auxiliar os educadores em como devem desenvolver um trabalho que irá contribuir para o processo de desenvolvimento do aluno.

Para tanto, utilizamos como procedimento metodológico a revisão bibliográfica não é mera repetição do que foi dito ou escrito sobre certo assunto, mas propicia o exame de um tema sob novo enfoque ou abordagem, chegando a conclusões inovadoras (LAKATOS; MARCONI, 2003, p. 183).

Assumimos tal procedimento metodológico, pois isso viabilizará atender o objetivo desse trabalho que é propiciar compreensão sobre a psicomotricidade funcional enquanto um elemento que contribua para que a criança execute movimentos corretos em instrumentos de percussão.

\section{CONCEITOS FUNCIONAIS DA PSICOMOTRICIDADE E O PROCESSO DE APRENDIZAGEM}

Atualmente, a sociedade brasileira de psicomotricidade tem realizado esforços para que seus profissionais possam atuar de forma séria e estruturada. Para a sociedade brasileira de psicomotricidade, esta é definida como "uma ciência que tem por objetivo o estudo do homem por meio do seu corpo em movimento, nas relações com seu mundo interno e externo".

Assim, compreendemos que a psicomotricidade considera o indivíduo como um ser físico, social e afetivo em constante transformação, uma vez que esse indivíduo está sempre em troca com o meio, modificando-o e modificando-se.

A psicomotricidade está associada ao processo de evolução do corpo, que é o objeto e sujeito de estudo. Por isso, é importante estabelecer esse paralelo.

Nessa perspectiva, veremos alguns dos conceitos utilizados na definição da 
psicomotricidade e todos objetivando a compreensão do desenvolvimento motor e psicomotor do ser humano.

Vítor da Fonseca definiu psicomotricidade e todo o processo de desenvolvimento psicomotor afirmando que:

A psicomotricidade visa
privilegiar a qualidade da
relação afetiva, a
mediatização, a
disponibilidade tônica, a
segurança gravitacional e
o controle postural, à
noção do corpo, sua
lateralização a
direcionalidade e a
planificação práxica,
enquanto componentes
essenciais e globais da
aprendizagem e do seu ato
mental concomitante.
Nela o corpo e a
motricidade sado
abordados como unidade
e totalidade do ser. O seu
enfoque é, portanto,
psicossomático, psico-
cognitivo, psiquiátrico,
somato-analítico, psico-
neurológico e psico-
terapêutico (FONSECA,
1996, p. 36).

Dalila M. M. De Costallat coloca a psicomotricidade como "ciência da educação, e enfoca esta unidade educando o movimento ao mesmo tempo em que põem em jogo as funções intelectuais" (COSTALLAT, 1974, p.1).

Jaques Chazaud conceitua a psicomotricidade como uma determinada organização funcional da conduta e da ação; correlativamente, é certo tipo de prática da reabilitação gestual (CHAZAUD, 1976, p.7).

Jean Le Boulch nos diz que a finalidade da educação psicomotora não é a aquisição de habilidades gestuais. Entretanto, o trabalho psicomotor tal qual o conhecemos, resulta numa melhor aptidão para a aprendizagem, dentro do respeito ao desenvolvimento da criança (LE BOULCH, 1987, p.15).

Coste (1992) coloca que o objetivo da psicomotricidade é dar ao indivíduo a possibilidade de dominar seu corpo, de economizar sua energia, de pensar seus gestos a fim de aumentar-Ihes a eficácia e a estética, de aperfeiçoar o seu equilíbrio. "O homem é o seu corpo" (COSTE, 1992, p. 9).

Meur e Staes (1984) nos esclarecem que - estudo da psicomotricidade pesquisa as ligações com a lateralidade, a estruturação espacial e a orientação temporal por um lado e, por outro, as dificuldades escolares de crianças de inteligência normal. Faz também com que se tome consciência das relações existentes entre o gesto e a afetividade (DE MEUR; STAES, 1984, p. $5)$.

Já para OLIVEIRA (1995, p. 9) a psicomotricidade se caracteriza por uma educação que se utiliza do movimento para atingir outras aquisições mais elevadas, como as intelectuais.

Assim, são muitas as definições sobre o termo psicomotricidade, mas o princípio do estudo é único: o desempenho motor do corpo, refletindo sua relação com o pensamento, o movimento e as ações.

A psicomotricidade tem suas bases num longo processo contemporâneo dos estudos de Dupré. Ele foi um dos primeiros a relacionar os estudos sobre as relações psíquicas e as relações motoras (COSTE, 1992).

Fonseca (1996), ratifica que o "termo" psicomotricidade surgiu pela primeira vez com o próprio Dupré, em 1920, quando entrelaçando relações psíquicas e as motoras, ou seja, movimento e pensamento.

Anteriormente, alguns médicos buscavam explicações para os fenômenos clínicos e psicológicos, contudo, seus esforços e pesquisas recaíram para o enfoque neurológico.

Estudos surgiram buscando a compreensão da gênese da psicomotricidade, muitos enfatizando os aspectos psicomotores para explicar o desenvolvimento do ser humano. Wallon, Piaget e Ajuriaguerra tiveram esta preocupação de aprofundar seus estudos para o campo do desenvolvimento. (FONSECA, 1996).

Um dos autores que mais estudou as inter-relações entre a motricidade e a percepção foi Piaget, por meio de ampla experimentação. Ele se preocupou com a relação evolutiva da psicomotricidade com a inteligência, nas formas de equilíbrio do pensamento (FONSECA, 1996).

Ainda para Piaget, a motricidade afeta a inteligência, antes mesmo da aquisição da linguagem. A inteligência verbal ou reflexiva apoia-se numa inteligência sensório-motora ou prática, que por seu lado se apoia nos hábitos e ações para combiná-las. Esse movimento 
proporciona os esquemas de assimilação, e organiza o real a partir das associações adquiridas.

Já Wallon se preocupou com a relação psicomotora, afeto e emoção; aprofundou o estudo das relações que unem o tono, o pano de fundo de todo ato motor, as tramas em que este se tece, e a emoção, isto é, a expressão mais primitiva dos seres que é a atividade de relação. Ele ainda nos mostra que a toda emoção estão vinculados, ao mesmo tempo, certo comportamento tônico, certas transformações características das atitudes e reações musculares, e viscerais e procurou formular as leis dessa inter-relação (COSTE, 1992).

A teoria Walloniana deu destaque para dimensão afetiva, mas o seu grande eixo é a motricidade, pois para ele o ato mental se desenvolve essencialmente a partir o ato motor, mediado pelo processo "cinético e postural". O primeiro correspondendo ao movimento visível, a mudança de posição do corpo, ou segmentos do corpo no espaço; o segundo, à manutenção da posição assumida (atitude) e à mímica (LA TAILLE, 1992, APUD FONSECA, 1996).

Ajuriaguerra contribui para consolidar as bases da evolução psicomotora. Ele redefiniu com precisão alguns aspectos não tão claros da obra de Wallon. Voltando sua atenção mais para o corpo e sua relação com o meio. Para ele, o processo evolutivo da criança está na conscientização do seu próprio corpo. "o corpo é uma totalidade e uma estrutura interna fundamental para o desenvolvimento mental, afetivo e motor da criança". As experiências e vivências corporais é que organizam a personalidade da criança.

"A vivência corporal não é senão o fator gerador das respostas adquiridas, onde se inscrevem todas as tensões e as emoções que caracterizam a evolução psicoafetiva da criança" (FONSECA, 1996).

Nos primeiros movimentos de estudo da psicomotricidade mantiveram-se dentro de uma proposta reeducativa. A reeducação sendo uma forma de estimular na criança, por exemplo, nas suas funções psicomotoras, que foram mal exploradas em seu desenvolvimento.

Porém, Piaget em seus estudos já se preocupava em estimular as crianças de forma adequada, respeitando cada fase do seu desenvolvimento. Assim, ele redimensionou as questões da psicomotricidade e não a limitou apenas a uma ação reeducativa, mas a uma primeira instância educativa.

Percebe-se que o processo evolutivo da criança está, portanto, relacionados à motricidade, afetividade e a inteligência. Wallon nos apresentava a motricidade como uma das origens da vida intelectual, e assim tornando-se fundamental para a educação das crianças.

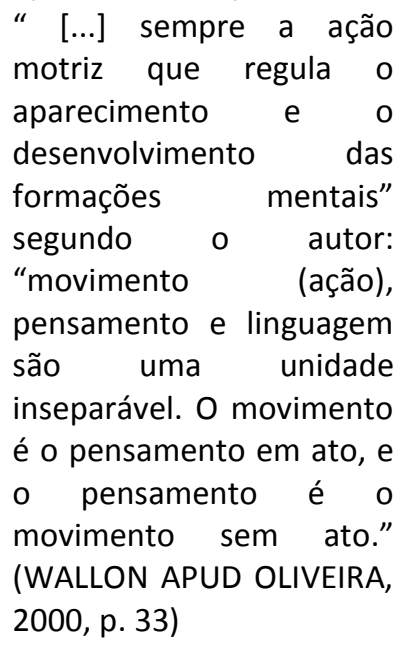

A psicomotricidade é um caminho, em que o indivíduo não é exclusivamente um ser motor nem um ser psíquico. Ele é psicomotor, ou seja, é uma articulação dos aspectos do ter, ser, querer, poder ser e fazer. Nessa perspectiva o estudo da psicomotricidade deve ser de grande relevância em diferentes áreas, por exemplo, a pedagogia uma vez que ela contribui diretamente no processo de desenvolvimento do indivíduo.

A educação psicomotora deve ser considerada como uma educação de base na escola primária. Ela condiciona todos os aprendizados préescolares; leva a criança a tomar consciência do seu corpo, da lateralidade, a situar-se no espaço, a dominar o tempo, a adquirir habilidade e coordenação de seus gestos e movimentos. A educação psicomotora deve ser praticada desde a mais tenra idade; conduzida com perseverança, permite inadaptações, difíceis de corrigir quando já 
estruturadas. (LE BOULCH, 1987, p. 235)

A abordagem da psicomotricidade junto à pedagogia irá permitir uma ampla compreensão da forma como a criança toma consciência do seu corpo e das possibilidades de se expressar por meio dele, localizando-se no tempo e no espaço. Ajuriaguerra (apud FONSECA, 1998, p. 332) reforça ser um erro estudar a psicomotricidade apenas por um prisma do plano motor, sem estar acompanhada de um plano mental. $E$ isso vale certamente para as demais áreas, em especial, da educação.

Para que ocorra um desenvolvimento integral e uniforme da criança, precisamos entender que, no decorrer do processo de aprendizagem, os elementos básicos da psicomotricidade (esquema corporal, estruturação espacial, lateralidade, orientação temporal e pré-escrita) são utilizados com frequência, sendo importantes para que a criança associe noções de tempo e espaço, conceitos, ideias, enfim se aproprie dos conhecimentos. Um problema em um destes elementos poderá prejudicar a aprendizagem, criando algumas barreiras.

Nessa perspectiva fica claro o quanto o profissional necessita ser habilitado por isso, 0 que justifica a defesa da inclusão do estudo da psicomotricidade na grade curricular dos cursos de educação, em especial, na pedagogia. O trabalho da educação psicomotora com as crianças deve prever a formação de base indispensável em seu desenvolvimento motor, afetivo e psicológico, dando oportunidade para que por meio de jogos, de atividades lúdicas, se conscientize sobre seu corpo. Através dessas atividades lúdicas a criança desenvolve suas aptidões perceptivas como meio de ajustamento do comportamento psicomotor. Portanto,

A psicomotricidade não é
exclusiva de um método,
ou de uma "escola" ou de
uma "corrente" de
pensamento, nem
constitui uma técnica, um
processo, mas visa fins
educativos pelo emprego
do movimento humano.
(AJURIAGUERRA, APUD
FONSECA, 1996, p. 332).

Segundo Piaget, todos os mecanismos cognitivos assentam-se na motricidade, para isso, esta se torna o meio, o instrumento facilitador de todas as formas de expressão verbal.

Freire também nos reforça a importância dos atos motores não apenas na relação da criança com o mundo, mas também na compreensão dessas relações. Segundo ele, a expressão corporal liga a atividade simbólica, as representações mentais, com o mundo real (concreto), com o qual o sujeito se relaciona. Ele ainda afirma que:

“[...] não se passa do
mundo concreto para a
representação mental
senão por intermédio da
ação corporal. A criança
transforma em símbolos
aquilo que pode vivenciar
corporalmente: o que ela
vê, cheira, pega, chuta,
aquilo que corre e assim
por diante". (FREIRE, 1996,
p. 20).

Percebemos, portanto, que o objetivo da educação psicomotora não se restringe somente ao conhecimento da criança sobre a imagem do seu corpo, ou seja, ela não se prende apenas ao conteúdo, mas contribui na descoberta estrutural da relação entre as partes e a totalidade do corpo, formando uma unidade organizada, instrumento da relação com a realidade. Assim, quanto mais cedo abordado no ambiente escolar mais os alunos poderão conhecer-se melhor, desenvolvendo a maturidade, a consciência e a inteligência apropriada ao processo de desenvolvimento integral do indivíduo. Le Boulch aponta o objetivo central da educação psicomotora:

O objetivo central da educação pelo movimento é contribuir para o desenvolvimento psicomotor da criança, da qual depende, ao mesmo tempo, a evolução de sua personalidade e o sucesso escolar. (LE BOULCH, 1984, p. 24).

A psicomotricidade inicialmente utiliza-se do mesmo paradigma da educação física das crianças, pois acompanhava a vertente da ginástica ao agrupar famílias de exercícios (equilíbrio, coordenação, lateralidade, orientação espacial, orientação temporal, ritmo). 
Atualmente, a psicomotricidade é a educação que se utiliza dos movimentos para atingir outras aquisições mais elaboradas, como as intelectuais, sociais, afetivas, motoras. Para isso utiliza-se de elementos básicos como esquema corporal, lateralidade, estruturação espacial e temporal, para que o desenvolvimento psicomotor ocorra através de exercícios motores em que o corpo se movimente e o sujeito perceba as diferentes noções de maneira interna. A psicomotricidade, portanto, visa oferecer às nossas crianças a livre expressão de seu ser, o estar em e o sentir-se bem.

A psicomotricidade funcional que tem como fundamento como finalidade sanar problemas do desenvolvimento motor melhorando as aprendizagens cognitivas e comportamental fazendo parte da educação psicomotora, vem corroborar para o desenvolvimento das crianças, sobretudo nos mais diversos movimentos que possa executar, já que assume como essencial o treinamento desses movimentos que culminam em um processo preciso e correto.

\section{A PSICOMOTRICIDADE NA PERCUSSÃO}

Abordaremos então a ideia de que a psicomotricidade na percussão é algo benéfico para os praticantes, os alunos no caso, e apontaremos através dos fatores psicomotores onde a utilizamos e onde podemos encontrar os seus déficits.

COSTALLAT (1978, p. 3) já destaca a importância da música na psicomotricidade, quando argumenta que "a música é um poderoso auxiliar, que facilita em grande parte a reeducação, pois ajuda a criar verdadeiros reflexos condicionados de tipo auditivo-motor".

$\mathrm{Na}$ percussão temos a possibilidade de fazer música através dos mais variados instrumentos que compõe a enorme família da percussão, como podemos fazer música através do nosso corpo, partindo para a área da percussão corporal. GAINZA (1988, p. 29) já destaca esta situação quando diz que

A ação musical implica num movimento, seja das cordas vocais e do aparelho fonador daquele que fala ou canta, seja do próprio corpo. No último caso, o corpo aparece como "instrumento produtor de som ou se "prolonga" através de um instrumento

musical propriamente dito.

A própria Violeta Gainza (1988) destaca que em alguns casos o instrumentista não consegue executar determinado trecho, não pela falta de capacidade, falta de técnica necessária, mas sim por causa de alguns conflitos, físicos ou psicológicos, que afetam o músico.

Vou me referir a música
não como uma atividade
terapêutica, que cura, faz
bem, mas sim como uma
manifestação direta de
conflitos, de aspectos
individuais que funcionam
de maneira inadequada ou
incompleta. A disfunção
musical poria, então, em
evidencia a existência de
problemas que deveriam
ser especialmente
solucionados e não
simplesmente percebidos,
como tem sucedido
frequentemente durante
as gerações que nos
precederam. (GAINZA,
1988, p. 43)

Tendo como referência essa informação que é dada por Gainza, analisaremos isoladamente cada fator psicomotor para apontar a sua importância na prática percussiva.

A tonicidade ou tônus muscular "é uma tensão dos músculos pela qual as posições relativas das diversas partes do corpo são corretamente mantidas e que se opõe as modificações passivas destas posições" (ALVES, 2012 , p. 44). Compreendemos a tonicidade como um estado de tensão ativa dos músculos que possibilita ao sujeito segurar objetos e aplicar a força necessária para as ações realizadas por ele.

Deste modo, na prática da percussão, podemos destacar que utilizamos a tonicidade para controlar a força necessária que será aplicada para segurar as baquetas e evitar que elas caiam da mão do estudante. Aplicar muita força, deixando a mão do estudante muito tensa, não se faz necessário e classifica-se como hipertonia.

A coordenação motora global (também chamada por alguns autores de ampla) "é a coordenação existente entre os grandes grupamentos musculares" (ALVES, 2012, p. 66). 
Podemos pensar na execução dos grandes grupos musculares, dos grandes membros.

Esse fator bem desenvolvido é muito importante para uma boa execução na bateria, por exemplo, aonde em muitos casos o baterista necessita utilizar os seus quatro membros de maneira distinta.

A coordenação motora fina "é uma coordenação segmentar, normalmente com a utilização das mãos exigindo precisão nos movimentos para a realização de tarefas complexas[...]" (ALVES, 2012, p. 66). Ao contrário da global, a coordenação motora fina trabalha com os pequenos grupos musculares, principalmente com as mãos e os dedos.

Neste caso é necessário este fator para o controle preciso da baqueta, e para alguns movimentos rápidos, para toques que exigem rapidez. Outra situação que exige a coordenação fina bem apurada é para a execução de instrumentos como o pandeiro ou o tamborim, onde é necessário o movimento de apenas um dedo para abafar ou soltar a pele do instrumento.

Para o esquema corporal Alves (2012) destaca como características: o equilíbrio, a independência dos membros em relação ao tronco e entre si, o controle muscular. Também são características a lentidão dos movimentos e os descontroles gestuais.

O músico/percussionista, tem que ter muito controle e precisão nos seus gestos e movimentos, para que a execução dos ritmos, ou das notas seja feito da maneira correta.

A lateralidade é um dos fatores mais complexos para definir pois existem várias definições com terminologias diferenciadas, porém ALVES (2012, p. 72) cita

Já para Baroja, Paret e Riesgo (1978), a definição de lateralidade está relacionada com 0 conhecimento corporal. $\mathrm{O}$ conhecimento do próprio corpo é de grande importância nas relações entre o eu e o mundo exterior, o que segundo Wallon é um elemento indispensável constituição personalidade.

O indivíduo conhecendo o corpo, cria possibilidades de execução de movimentos para o mesmo, como movimentos paralelos e alternados, por exemplo. A lateralidade também diz respeito a capacidade do indivíduo de compreender que a leitura acontece da esquerda para a direita.

Assim, a lateralidade requer que 0 percussionista execute movimentos com os dois lados do corpo, seja de forma paralela ou alternada. Também está relacionada com a percepção do aluno em entender que a leitura musical acontece da esquerda para a direita e que ao final da linha, devemos pular para a pauta de baixo.

$\mathrm{Na}$ estruturação espaço-temporal, ou espacial, a ideia defendia por ALVES (2012, p. 79) "primeiro, a criança percebe a posição de seu próprio corpo no espaço. Depois a posição dos objetos em relação a si mesma e, por fim, aprende a notar as relações das posições dos objetos entre si". Entendemos então que a criança começa a compreender situações e conceitos como: perto, longe, antes, depois, em cima, embaixo.

Neste contexto, entendemos que esse fator psicomotor auxilia o estudante de percussão, se determinada nota vem antes ou depois da nota de um outro amigo, por exemplo, quantas notas são. Muito comum encontrar alunos com essa dificuldade quando realizamos a atividade de eco musical, pois em muitos casos o aluno não consegue compreender quantas notas tocamos, ou como as organizamos.

\section{CONSIDERAÇÕES FINAIS}

Mediante todas as ideias que foram aqui expostas, concluímos que é possível apontar onde os fatores psicomotores atuam diretamente no estudante de percussão.

Compreendemos que em muitos casos, o aluno não toca corretamente o que é pedido, não por falta de técnica, mas por causa de déficits psicomotores, que através da psicomotricidade funcional serão sanados.

Então, para que isso ocorra é necessário que o educador musical esteja preparado e atento para observar as situações causadas por aluno. GAINZA (1988, p. 43) destaca isso,

Toda atividade musical é uma atividade projetiva, algo que o indivíduo faz e mediante a qual se mostra; permite, portanto, que o observador treinado observe tanto os aspectos que funcionam bem no indivíduo, como aqueles aspectos mais incompletos 


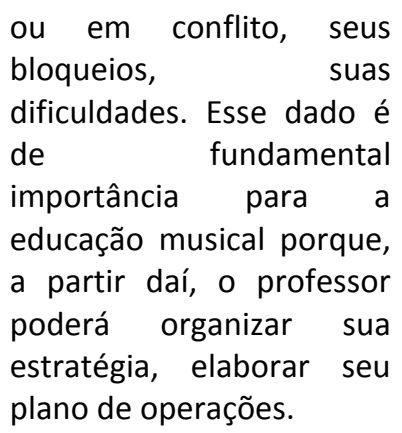

\section{REFERÊNCIAS}

ALVES, Fátima. Psicomotricidade: corpo, ação e emoção. Rio de Janeiro: Wak, 2012.

CHAZAUD, Jaques. Introdução á Psicomotricidade. São Paulo: Manole, 1976.

COSTALLAT, Dalila M. de. Psicomotricidade I. Porto Alegre: Globo, 1974.

COSTE, Jean-Claude. A Psicomotricidade. Tradução: Álvaro Cabral. 4.ed. Rio de Janeiro, Guanabara Koogan, 1992.

DE MEUR, A.; STAES, L. Psicomotricidade: educação e reeducação. São Paulo: Manole, 1984.

FONSECA, Vitor. Psicomotricidade. 4. ed. São Paulo: Martins Fontes, 1996.

FREIRE, Paulo. Pedagogia da autonomia: saberes necessários à prática educativa. 29. ed. São Paulo: Paz e Terra, 1996. (Coleção leitura).

GAINZA, Violeta H. de. Estudos de psicopedagogia musical. 3. ed. São Paulo: Summus, 1988.

LAKATOS, E. M.; MARCONI, M. A. Fundamentos de metodologia científica.

São Paulo: Atlas, 2003.

LA TAILLE, Yves de; OLIVEIRA, Martha Kohl de; DANTAS, Heloysa. Piaget, Vygotsky e Wallon: teorias psicogenéticas em discussão. São Paulo: Summos, 1992.

LE BOULCH, J. O desenvolvimento psicomotor do nascimento até 6 anos. Porto Alegre: Artes Médicas, 1984.

OLIVEIRA, Gislene de Campo. Psicomotricidade: educação e reeducação num enfoque psicopedagógico. 12. ed. Rio de Janeiro: Vozes, 2007.
TAVARES, M. L. A psicomotricidade no processo de aprendizagem. 2007. Disponível em: http://www.avm.edu.br/monopdf/7/Michelline\% 20De\%20Lima\%20Tavares.pdf. Acesso em: abr. 2016.

Recebido para publicação em: 26/04/2016

Revisado em: 29/04/2016

Aceito em: 02/05/2016 